\title{
On Your Level
}

\author{
Megan Abbott ${ }^{1}$
}

Received: 21 March 2016 / Accepted: 23 March 2016/Published online: 11 April 2016

(C) Academic Psychiatry 2016

4 feet.

That is the difference between my head and yours

Me standing above, you lying near the floor

I know it seems like we are miles apart

You have your pain, I have your chart

4 feet.

I am surprised of the difference it makes.

This space is filled with silent moments to break

The bruises on your face everyone can see

Inside damage you can hide from me

4 feet.

The trauma you have faced is too much to bear

You turn away from me, not wanting to share

This length between us is starting to grow

You won't let your emotions show

4 feet.

The gap is too much; I can see you can't cope I sink to my knees in despair more than hope

But that seems to work, you look at my face

I can feel it shrinking, this space

0 feet.

At this point we both look fairly disheveled

But we talk as equals, on the same level

I see now I needed to come to you

Face to face we would journey through

Megan Abbott

mabbott@bcm.edu

1 Baylor College of Medicine, Houston, TX, USA 